\title{
Fibroblast growth factor-2 alters the nature of extinction
}

\author{
Bronwyn M. Graham ${ }^{1}$ and Rick Richardson \\ School of Psychology, University of New South Wales, Sydney 2052, Australia
}

\begin{abstract}
These experiments examined the effects of the NMDA-receptor (NMDAr) antagonist MK801 on reacquisition and reextinction of a conditioned fear that had been previously extinguished before injection of fibroblast growth factor-2 (FGF2) or vehicle. Recent findings have shown that relearning and re-extinction, unlike initial learning and extinction, do not depend on NMDAr activation. Three experiments demonstrated that FGF2 prevents the switch from NMDArdependent to NMDAr-independent reacquisition and re-extinction, suggesting that FGF2 may lead to the partial erasure of the original fear memory. These findings add to a growing body of work suggesting that FGF2 may be a novel pharmacological enhancer of exposure therapy for humans with anxiety disorders.
\end{abstract}

Fibroblast growth factor-2 (FGF2) is a neurotrophic factor that regulates neural development, regenerative plasticity, and neurogenesis (Unsicker et al. 1991). Recently, systemic FGF2 has been shown to enhance long-term memory for contextual fear (Graham and Richardson 2009a, 2010a) and extinction of conditioned fear in rats (Graham and Richardson 2009b, 2010b). Extinction occurs when a conditioned stimulus (CS) is repeatedly presented in the absence of the unconditioned stimulus (US), which substantially reduces conditioned fear responding. The finding that fear often returns after extinction when the CS is presented in a different context to that of extinction (renewal) (Bouton and Bolles 1979a), or when a mild unsignaled stressor precedes the test (reinstatement) (Bouton and Bolles 1979b), has led to the widely-held belief that extinction involves the formation of a new context-specific CS-no US memory that inhibits the (intact) original fear memory.

Our recent studies suggest that FGF2 does not facilitate the formation of a context-specific extinction memory. Specifically, FGF2-treated rats show significantly attenuated reinstatement and renewal (Graham and Richardson 2009b, 2010b), even when control rats are given double the amount of extinction training to equate the strength of extinction between FGF2-treated and control rats. This suggests that FGF2 may change the quality of extinction, possibly by weakening the original fear memory. The present experiments assessed this possibility behaviorally by exploiting recent findings regarding the molecular substrates underlying re-extinction, which refers to the process of relearning extinction following reacquisition of fear to an extinguished cue. Converging evidence strongly suggests that initial extinction and re-extinction do not depend on the same neural or molecular mechanisms. For example, unlike initial extinction, re-extinction is not impaired by NMDAr antagonists MK801 or DL-APV (Laurent et al. 2008; Langton and Richardson 2009, 2010). These experiments suggest that relearning to inhibit fear does not depend on NMDAr activity.

The present experiments assessed the effect of MK801 on the re-extinction of conditioned fear that had been extinguished with FGF2 or its vehicle. If FGF2 simply enhances context-dependent new learning during extinction, then re-extinction in FGF2-treated rats, as in vehicle-treated rats, should be

\footnotetext{
${ }^{1}$ Corresponding author.

E-mail bgraham@psy.unsw.edu.au; fax 61-2-93853641.

Article is online at http://www.learnmem.org/cgi/doi/10.1101/Im.2006511.
}

NMDAr-independent. However, if treatment with FGF2 alters the nature of extinction, then these rats may not exhibit this transition. Rats were 23 days of age at the start of all experiments; rats this age exhibit adult-like extinction (Kim and Richardson 2010). In Experiment 1, rats were fear conditioned with two white-noise CS and footshock US pairings on day 1 . On day 2 rats received 45 CS-alone extinction trials, immediately followed by $0.02 \mathrm{mg} / \mathrm{kg}$ body weight FGF2 or vehicle. On day 3 rats were given one CS-US pairing during reacquisition training. On day 4 rats received $0.1 \mathrm{mg} / \mathrm{kg}$ body weight MK801 or saline, and $10 \mathrm{~min}$ later they received $45 \mathrm{CS}$-alone re-extinction trials. On day 5 rats were tested for re-extinction retention, involving a 1 min adaptation period followed by a $2 \mathrm{~min}$ CS presentation. Rats were scored for the percentage of time spent freezing during the adaptation period (pre-CS), and the CS presentations at extinction, reacquisition, re-extinction, and test as an index of fear (Fanselow 1980). Table 1 presents the experimental timeline for all experiments.

There were no group differences in pre-CS freezing prior to extinction training (i.e., no significant main effects or interaction; $P s \geq 0.15$; see Table 2 for pre-CS freezing for all experiments). Furthermore, all groups exhibited similar levels of conditioned fear and similar rates of extinction; an extinction-drug by re-extinction-drug by extinction block mixed-design analysis of variance (ANOVA) revealed a significant effect of block $\left(F_{(8,432)}=60.42, P<0.0001\right)$, with no effects of group or interaction ( $P \mathrm{~s} \geq 0.07$; Fig. $1 \mathrm{~A})$. In addition, all groups exhibited similar levels of extinction retention, as there were no group differences in pre-CS or CS-elicited freezing during reacquisition $(P \mathrm{~S} \geq 0.16$; Table 2; Fig. 1B). This is consistent with previous findings that vehicle-treated rats exhibit comparable levels of extinction to FGF2-treated rats following a large number of extinction trials (Graham and Richardson 2009b, 2010b).

During re-extinction training MK801-treated rats exhibited significantly less pre-CS freezing than saline-treated rats; an ANOVA revealed a significant effect of re-extinction drug $\left(F_{(1,54)}=8.9, P=0.004\right)$, but no effect of extinction drug and no interaction of the two on pre-CS freezing prior to re-extinction training ( $P s \geq 0.43$; Table 2). During re-extinction training, CS-elicited freezing decreased across blocks for all groups (Fig. 1C); an extinction-drug by re-extinction drug by re-extinction block mixed-design ANOVA revealed a significant effect of block $\left(F_{(8,432)}=32.68, P<0.0001\right)$. There was also a significant effect of re-extinction drug $\left(F_{(1,54)}=75.9, P<0.0001\right)$, due to rats given MK801 exhibiting significantly less freezing 
during re-extinction training. There was no effect of extinction drug and no significant interaction ( $P \mathrm{~s} \geq 0.53$ ). The findings that MK801-treated rats exhibited reduced freezing throughout reextinction is consistent with previous reports (Lee et al. 2006; Chan and McNally 2009; Langton and Richardson 2009) that MK801 induces hyperactivity and reduces freezing.

An ANOVA revealed no significant effects of extinction drug or re-extinction drug on pre-CS freezing prior to test $(P s \geq$ 0.49). However, there was a significant interaction $\left(F_{(1,54)}=6.32, \quad P=0.015\right)$, due to FGF2-treated rats that received MK801 prior to re-extinction exhibiting higher pre-CS freezing than FGF2-treated rats that received saline prior to re-extinction $\left(t_{(27)}=2.1, P=0.046\right.$; Table 2$)$. Vehicle-treated rats did not differ from each other, regardless of the drug injected prior to re-extinction $(P=0.16)$. CS-elicited freezing at test is shown in Figure 1D. An ANOVA yielded a significant effect of extinction drug $\left(F_{(1,54)}=4.5, P=0.039\right)$, no effect of re-extinction drug $(P=0.1)$, and a significant extinction drug by re-extinction drug interaction $\left(F_{(1,54)}=5.65, P=0.021\right)$. This interaction was due to FGF2-treated rats that received MK801 prior to re-extinction exhibiting significantly higher CS-elicited freezing than FGF2-treated rats that received saline prior to re-extinction $\left(t_{(27)}=3.02, P=0.006\right)$. Vehicle-treated rats did not differ from each other, regardless of the drug injected prior to re-extinction (Ps $\geq 0.65$ ). Therefore, the results of Experiment 1 demonstrated that FGF2 administration after initial extinction causes subsequent re-extinction to remain NMDAr-dependent.

In order to ensure that the results obtained in Experiment 1 were due to the effects of FGF2 on extinction, rather than due to the effects of prior exposure to FGF2 and MK801 per se, in Experiment 2 rats received FGF2 immediately or $4 \mathrm{~h}$ after extinction. All rats were then retrained to fear the CS, and all were given MK801 prior to re-extinction training. We have previously demonstrated that FGF2 does not enhance extinction when administered $4 \mathrm{~h}$ post-extinction training (Graham and Richardson $2009 \mathrm{~b}$ ) and so if the results of the first experiment were due to the effect of FGF2 on extinction, rather than due to some nonspecific effect of FGF2 and MK801 exposure, MK801 should impair re-extinction retention for the FGF2-immediate group but not for the FGF2 $-4 \mathrm{~h}$ group.

An independent-samples $t$-test revealed no significant effect of group on pre-CS freezing levels prior to extinction training $(P=0.41$; Table 2$)$. A group by extinction block mixed-design ANOVA revealed a significant effect of block $\left(F_{(8,144)}=13.57, P<0.0001\right)$, but no effect of group and no interaction of group-by-block $(P s \geq 0.41)$ on CSelicited freezing throughout extinction training, indicating that both groups exhibited similar levels of conditioned fear and similar rates of extinction (Fig. 2A). Furthermore, both groups exhibited similar levels of extinction retention as there were no group differences in pre-CS or CS-elicited freezing during reacquisition ( $P s \geq 0.16$; Table 2; Fig. 2B). In addition, both groups exhibited similar rates of re-extinction as there was no effect of group on pre-CS
Table 2. Mean ( \pm SEM) pre-CS percent freezing prior to extinction, test, reacquisition, and re-extinction (where relevant) for all experiments

\begin{tabular}{lllll}
\hline Experiment & \multicolumn{3}{c}{ Group } \\
\hline Experiment 1 & Vehicle/MK801 & Vehicle/Saline & FGF2/MK801 & FGF2/Saline \\
Extinction & $34.6(5.62)$ & $26.9(6.34)$ & $35(5.5)$ & $24.9(6.5)$ \\
Reacquisition & $13.7(4.19)$ & $8.9(3.69)$ & $8.6(3.56)$ & $6.8(2.48)$ \\
Re-extinction & $18.6(3.86)$ & $33.4(6.6)$ & $24.1(3.41)$ & $38.1(5.6)$ \\
Test & $8.6(3.97)$ & $20.3(6.91)$ & $27.4(8.11)$ & $9.7(3.07)$ \\
Experiment 2 & FGF2-Imm & FGF2-4 hrs & & \\
Extinction & $52.5(12.54)$ & $39.1(10.0)$ & & \\
Reacquisition & $9.8(4.15)$ & $3.1(1.88)$ & & \\
Re-extinction & $25.2(7.98)$ & $18.5(7.14)$ & & \\
Test & $18(9.72)$ & $10.5(7.83)$ & & \\
Experiment 3 & Vehicle/MK801 & Vehicle/Saline & FGF2/MK801 & FGF2/Saline \\
Extinction & $25(9.17)$ & $49.9(9.34)$ & $38.7(8.89)$ & $38.5(10.72)$ \\
Reacquisition & $0.5(0.37)$ & $2.6(1.32)$ & $2.3(0.87)$ & $4.5(2.15)$ \\
Test & $37.7(10.56)$ & $49.1(7.59)$ & $17.1(4.28)$ & $45.9(8.84)$ \\
\hline
\end{tabular}



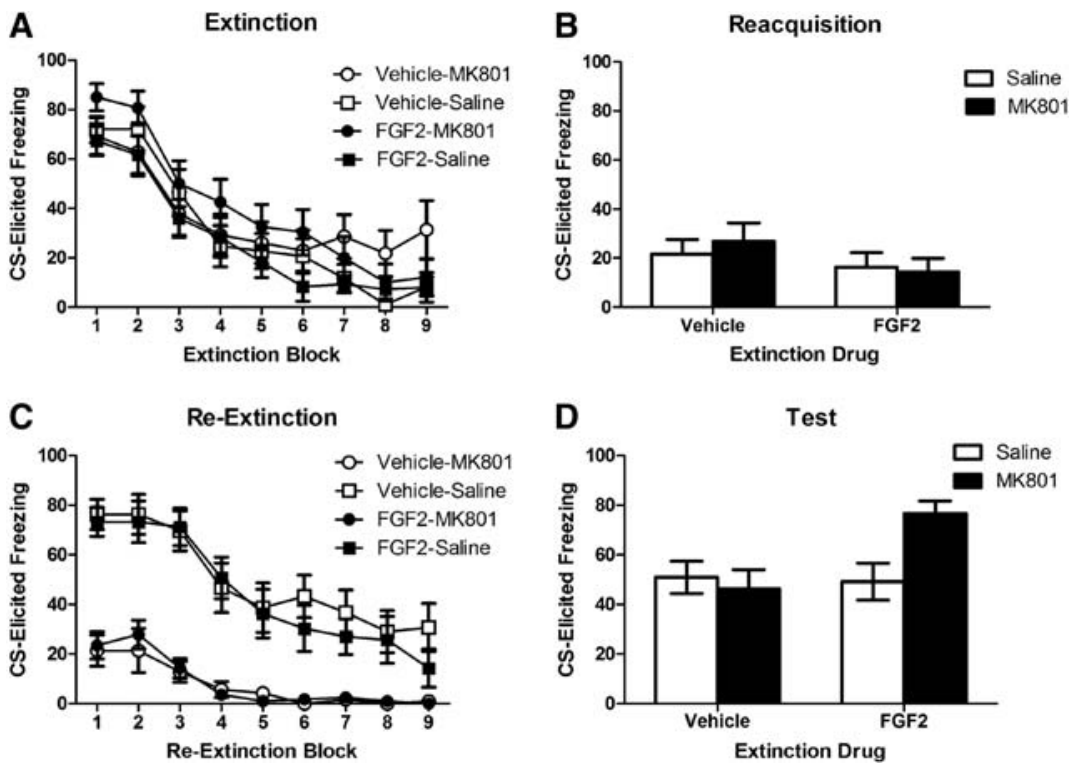

Figure 1. (A) Mean ( \pm SEM) CS-elicited freezing during extinction training in Experiment 1. Each block consists of five extinction trials. Rats were in one of four groups: Vehicle/MK801 $(n=14)$, Vehicle/Saline $(n=15)$, FGF2/MK801 $(n=14)$, and FGF2/Saline $(n=15)$. (B) Mean ( \pm SEM) CS-elicited freezing during reacquisition in Experiment 1. (C) Mean ( \pm SEM) CS-elicited freezing during re-extinction training in Experiment 1. Each block consists of five extinction trials. $(D)$ Mean ( \pm SEM) CS-elicited freezing during test in Experiment 1.

questions: Is reacquisition of cued fear following extinction NMDAr-independent, and if so, does FGF2 prevent the switch from NMDAr-dependent to NMDAr-independent reacquisition? Rats received fear conditioning on day 1 and fear extinction on day 2 (followed by FGF2 or vehicle) as in Experiment 1. On day 3 rats received MK801 or saline, and 10 min later they received reacquisition training. All rats were tested for reacquisition retention on day 4 (where greater levels of freezing indicate greater retention).

An extinction drug by reacquisition drug ANOVA revealed no group differences in pre-CS freezing during the adaptation period prior to extinction (i.e., no significant main effects or interaction; $P s \geq 0.2$; Table 2). An extinction drug by reacquisition drug by extinction block mixed-design ANOVA revealed a significant effect of block $\left(F_{(8,328)}=69.16\right.$, $P<0.0001)$, with no effect of group or interaction $(P \mathrm{~s} \geq 0.1)$, meaning that all groups exhibited similar levels of conditioned fear and similar rates of extinction (Fig. 3A). Furthermore, there were no differences between groups in levels of pre-CS or CS-elicited freezing during reacquisition training $(P \mathrm{~s} \geq 0.11$; Table 2; Fig. 3B). At test following reacquisition, there was a significant main effect of reacquisition drug on levels of pre-CS freezing $\left(F_{(1,41)}=6.28, \quad P=\right.$ 0.016; Table 2). This was due to FGF2-treated rats that received MK801 prior to reacquisition exhibiting significantly less freezing than FGF2-treated rats that received saline prior to reacquisition $\quad\left(t_{(21)}=3.02, \quad P=0.007\right)$.
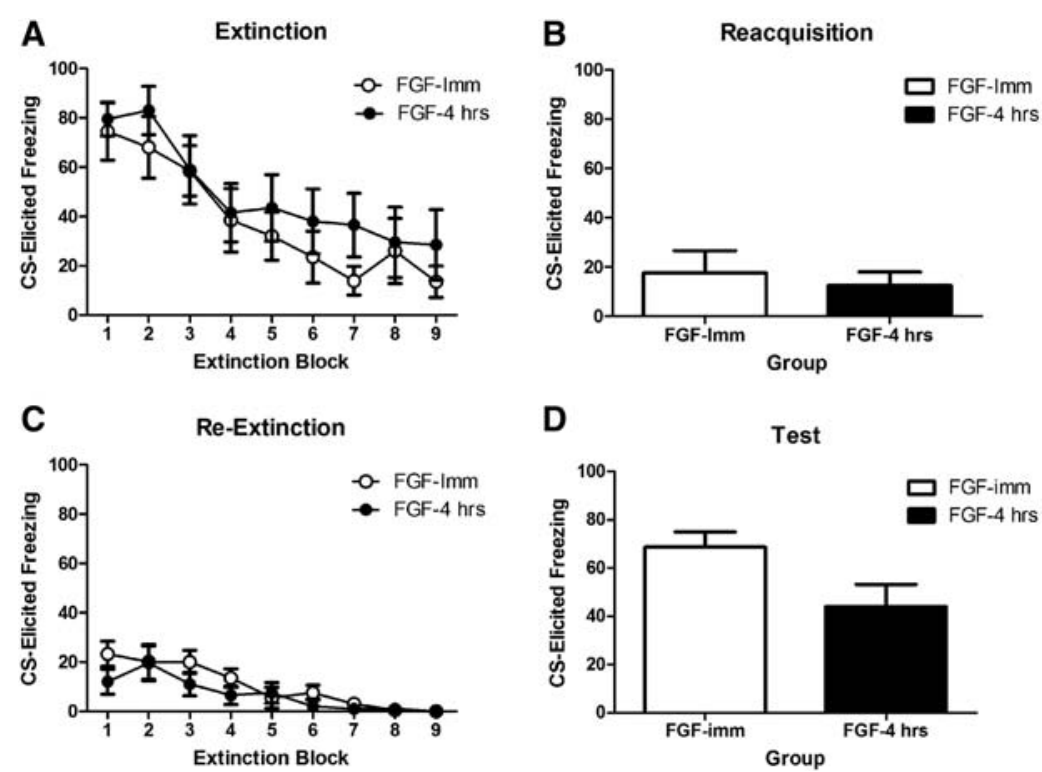

D

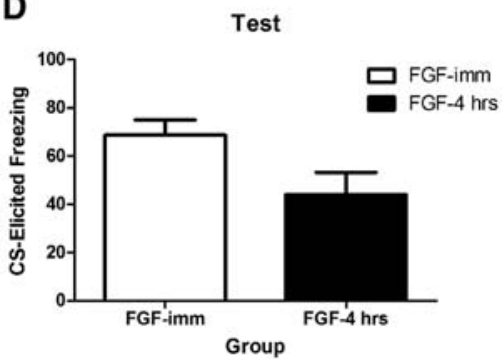

Figure 2. (A) Mean ( \pm SEM) CS-elicited freezing during extinction training in Experiment 2. Each block consists of five extinction trials. Rats were in one of two groups: FGF2-Imm, and FGF2 $-4 \mathrm{~h}$ $(\mathrm{ns}=10)$. (B) Mean ( \pm SEM) CS-elicited freezing during reacquisition in Experiment 2. (C) Mean ( \pm SEM) CS-elicited freezing during re-extinction training in Experiment 2. Each block consists of five extinction trials. $(D)$ Mean ( \pm SEM) CS-elicited freezing during test in Experiment 2. 

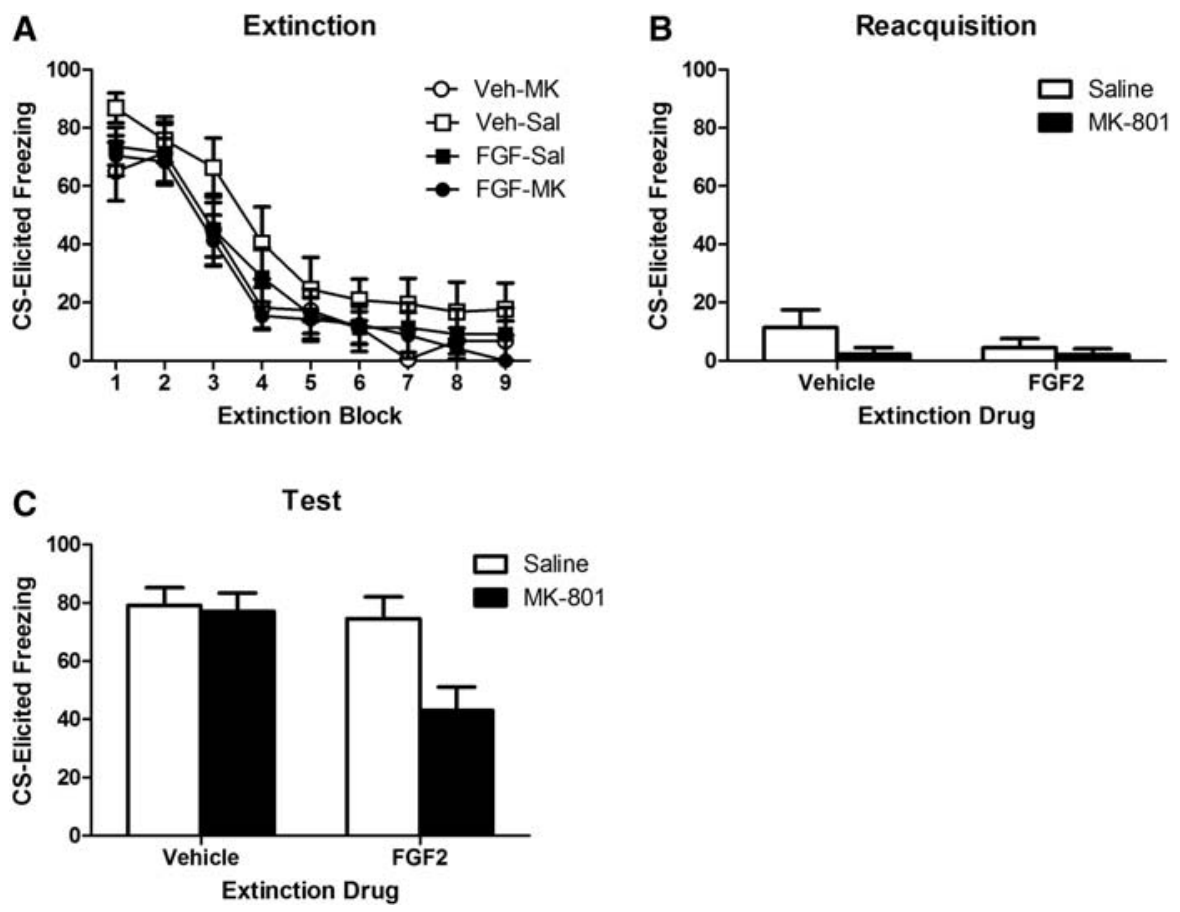

Figure 3. (A) Mean $( \pm$ SEM) CS-elicited freezing during extinction training in Experiment 3. Each block consists of five extinction trials. Rats were in one of four groups: Vehicle/MK801 $(n=11)$, Vehicle/Saline $(n=11)$, FGF2/MK801 $(n=12)$, and FGF2/Saline $(n=11)$. (B) Mean ( \pm SEM) CS-elicited freezing during reacquisition in Experiment 3. (C) Mean ( \pm SEM) CS-elicited freezing during test in Experiment 3.

Further, these results cannot be due to FGF2 impairing reextinction or reacquisition because FGF2-treated rats that received saline exhibited comparable re-extinction and reacquisition retention to vehicle-treated rats. Finally, these results cannot be due to nonspecific effects of combined FGF2 and MK801 exposure because FGF2 only prevented the switch to NMDAr-independent re-extinction when it was administered immediately and not $4 \mathrm{~h}$ after extinction training.

It should be noted that the variability in pre-CS levels of freezing across the three experiments reported here is likely due to the fact that all procedures took place in the same context and so during conditioning rats would have acquired fear of the $\mathrm{CS}$ and the context. Although somewhat more variable than the findings regarding CS-elicited freezing, the findings regarding pre-CS levels of freezing are generally consistent with the interpretation that extinction combined with FGF2 prevents the switch from NMDAr-dependent to NMDAr-independent reacquisition and re-extinction. For example, in Experiment 1 FGF2-treated rats that received MK801 prior to re-extinction exhibited higher pre-CS as well as CS-elicited freezing, suggesting that MK801 impaired re-extinction to both the context and the CS. Likewise, in Experiment 3 FGF2-treated rats that received MK801 prior to reacquisition exhibited lower pre-CS as well as CS-elicited freezing at test, suggesting that MK801 impaired reacquisition to both the context and the CS. In Experiment 2, however, no differences in pre-CS freezing at test were found. The effect of MK801 on contextual learning in FGF2-treated rats may be less robust due to the CS being a better predictor of the US than the context.

One explanation of the present findings is that during reacquisition training FGF2-treated rats form a new excitatory representation of the CS-US association (a process that is impaired by MK801), such that when they are re-extinguished they are actually extinguishing this association for the first time (a process associated with an increase in neurotrophic factors (Yuzaki et al. 1994). Furthermore, FGF2 exerts control over calcineurin activation (Boxer et al. 1999), which is one of the molecular signals involved in depotentiation (Lin et al. 2003b). Regardless of the mechanism, the present findings illustrate a novel way to assess the impact of a drug on the quality of extinction. Moreover, together with our previous findings that FGF2 reduces relapse, these experiments provide additional support for the idea that FGF2 may be a potentially useful pharmacological enhancer of exposure therapy in anxiety disorders, as they suggest that FGF2 may partially erase the original fear memory.

\section{Acknowledgments}

This research was supported by Discovery Project grants from the Australian Research Council (DP0985554) to R.R. and an Australian Postgraduate Award to B.M.G.

\section{References}

Bouton ME, Bolles RC. 1979a. Contextual control of the extinction of conditioned fear. Learn Motiv 10: $445-466$.

Bouton ME, Bolles RC. 1979b. Role of conditioned contextual stimuli in reinstatement of extinguished fear. J Exp Psychol Anim Behav Process 5: $368-378$.

Boxer AL, Moreno H, Rudy B, Ziff EB. 1999. FGF-2 potentiates $\mathrm{Ca}^{2+}$-dependent inactivation of NMDA receptor currents in hippocampal neurons. J Neurophysiol 82: 3367-3377.

Chan WYM, McNally GP. 2009. Conditioned stimulus familiarity determines effects of MK- 801 on fear extinction. Behav Neurosci 123: $303-314$.

Fanselow MS. 1980. Conditional and unconditional components of postshock freezing. Pavlov J Biol Sci 15: 177-182.

Graham BM, Richardson R. 2009a. Acute systemic fibroblast growth factor-2 enhances long- term memory in developing rats. Neurobiol Learn Mem 91: 424-430. 
Graham BM, Richardson R. 2009b. Acute systemic fibroblast growth factor-2 enhances long-term extinction of fear and reduces reinstatement in rats. Neuropsychopharmacology 34: 1875-1882.

Graham BM, Richardson R. 2010a. Early-life exposure to Fibroblast Growth Factor-2 facilitates context-dependent long-term memory in developing rats. Behav Neurosci 124: 337-345.

Graham BM, Richardson R. 2010b. Fibroblast Growth Factor-2 enhances extinction and prevents renewal of conditioned fear. Neuropsychopharmacology 35: 1348-1355.

Kim JH, Richardson R. 2010. New findings on extinction of conditioned fear early in development: Theoretical and clinical implications. Biol Psychiatry 67: 279-303.

Langton JM, Richardson R. 2008. d-cycloserine facilitates extinction the first time but not the second time: An examination of the role of NMDA across the course of repeated extinction sessions. Neuropsychopharmacology 33: 3096-3102.

Langton JM, Richardson R. 2009. The role of context in the re-extinction of learned fear. Neurobiol Learn Mem 92: 496-503.

Langton JM, Richardson R. 2010. The temporal specificity of the switch from NMDAr-dependent extinction to NMDAr-independent re-extinction. Behav Brain Res 208: 646-649.

Langton JM, Kim JH, Nicholas J, Richardson R. 2007. The effect of the NMDA receptor antagonist MK-801 on the acquisition and extinction of learned fear in the developing rat. Learn Mem 14: $665-668$.

Laurent V, Marchand AR, Westbrook RF. 2008. The basolateral amygdala is necessary for learning but not relearning extinction of context conditioned fear. Learn Mem 15: 304-314.

Lee JL, Milton AL, Everitt BJ. 2006. Reconsolidation and extinction of conditioned fear: Inhibition and potentiation. J Neurosci 26: 10051-10056.

Lin C, Yeh S, Lu H, Gean P. 2003a. The similarities and diversities of signal pathways leading to consolidation of conditioning and consolidation of extinction of fear memory. J Neurosci 23: 8310-8317.

Lin C, Lee C, Gean P. 2003b. Involvement of a calcineurin cascade in amygdala depotentiation and quenching of fear memory. Mol Pharmacol 63: 44-52.

Unsicker K, Grothe C, Otto D, Westermann R. 1991. Basic fibroblast growth factor in neurons and its putative functions. Ann N Y Acad Sci 638: 300-305.

Yuzaki M, Furuichi K, Mikoshiba K, Kagawa Y. 1994. A stimulus paradigm inducing long- term desensitization of AMPA receptors evokes a specific increase in BDNF mRNA in cerebellar slices. Learn Mem 1: 230-242.

Received September 8, 2010; accepted in revised form October 25, 2010. 


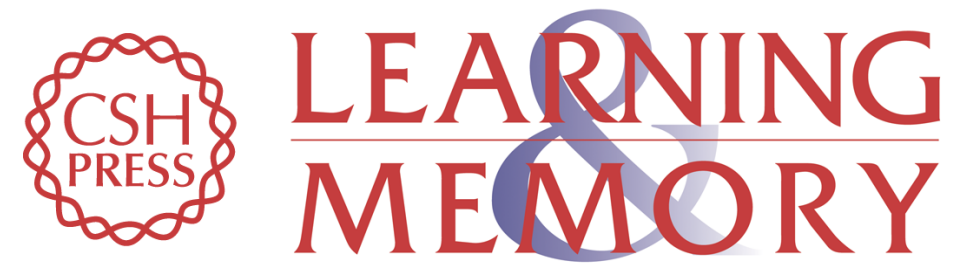

\section{Fibroblast growth factor-2 alters the nature of extinction}

Bronwyn M. Graham and Rick Richardson

Learn. Mem. 2011, 18:

Access the most recent version at doi:10.1101/lm.2006511

References This article cites 20 articles, 6 of which can be accessed free at: http://learnmem.cshlp.org/content/18/2/80.full.html\#ref-list-1

License

Email Alerting Receive free email alerts when new articles cite this article - sign up in the box at the Service top right corner of the article or click here. 